\title{
Hopes for planetary boost
}

\section{Tokyo}

A MAJOR shift in Japan's space policy may soon free the Institute of Space and Astronautical Science (ISAS) from limits on the size of its launch vehicles, enabling it to begin laying ambitious plans to send Japanese space probes to the planets. The change in policy is proposed in a 10 -year plan submitted by the long-term policy committee of the Space Activities Commission last week. The commission is expected to reach a final decision on the proposal by the middle of June.

The limit on ISAS's rockets was fixed 23 years ago when the National Space Development Agency (NASDA) was being set up to manage Japan's commercial space programme. ISAS (then part of Tokyo University) was allowed to maintain its independent, academic space research programme on condition that its home-developed solid-fuel rockets did not get too big - a limit of 1.41 metres tail diameter was set.

ISAS engineers have shown great ingenuity in working within the limit. In 1986 they sent two probes to Halley's comet and next year they plan to launch a probe to the Moon. But beyond the lunar probe, little more can be done with a small rocket.

For the past two years, the long-term policy committee has been considering proposals for a bigger rocket for ISAS, an unmanned shuttle to be built by NASDA and Japanese manned space flight. A bigger rocket for ISAS has been a contentious issue because some would like to see NASDA's $\mathrm{H}-2$ liquid fuel rocket, which is currently under development, used for planetary missions.

In the 10 -year policy submitted to the commission last week, it is stated that ISAS should be allowed to build rockets that conform to the safety limits of the institute's Kagoshima space centre.

Although no specific size of rocket is mentioned, this will in effect allow ISAS to build a rocket that breaches the 1.41metre limit. The committee's decision was made on the grounds that this is the most efficient and economical way to make use of Japan's rocket launch capability.

The rocket envisaged by ISAS will have a tail diameter of 2.5 metres, will be three times more powerful than the institute's present largest rocket, the Mu 3S-II, and will be able to place a 2 -ton payload in low Earth orbit, slightly less than NASDA's present $\mathrm{H}-1$ rocket. Development costs are expected to be about $¥ 15,000-20,000$ million (\$108-\$144 million) with a price for each rocket of $¥ 5,000-5,500$ million cheap by anybody's standards but it will require a significant boost in ISAS's annual budget from the Ministry of Education, Science and Culture (MESC). If the Space Activities Commission

\section{EUREKA train drives collaboration}

Paris

ON the initiative of the French ministry for research and technology, an 'exhibition train', featuring Europe's EUREKA programme for cross-frontier industrial collaboration in technology research, is set to wind its way through France, West Germany, Italy and Spain.

The initiative is both a celebration of the success of EUREKA - the brainchild of the French research minister, Hubert Curien - and an effort to solicit new proposals from regional industries.

The French government and industry have contributed almost 40 per cent of EUREKA's FF26,000 million $\mathbf{\$ 4 , 0 0 0}$ million) total cost since it was set up in $\mathbf{1 9 8 5}$.

The 13-day train journey, with eight stop-overs for seminars, will end in Lyons on 19 June to coincide with a conference on 'EUREKA in the regions'. On the same day, European research ministers attending EUREKA's ministerial meeting in Vienna will announce a new batch of projects. Out of more than 100 proposals already received, over 60 are expected to be approved.

Although not officially on the Vienna agenda, the new JESSI semiconductor programme of the European Commission (EC), which has not yet received full budget approval, will undoubtedly be dis-

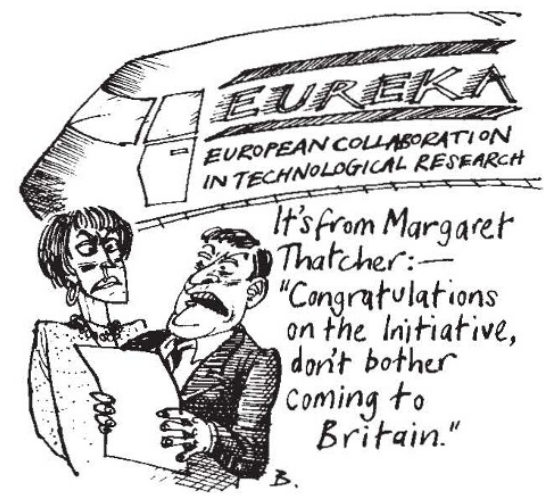

cussed. It is intended that JESSI link up with EUREKA and the EC information technology programme, ESPRIT, but no decision has so far been reached. Reluctant to be pinned down, Curien said that the French government will "do its best to see that JESSI gets the money it needs".

Peter Coles gives approval and MESC provides the funds, the rocket could be ready for test launch in 1994, according to Jun Nishimura, director-general of ISAS. Among the missions being considered for the new rocket are a lunar probe that would drop penetrators containing seismometers into the lunar surface to measure 'moonquakes', a probe to Venus that could release a balloon into the Venusian atmosphere, and a mission to collect dust from a comet and bring it back to Earth for analysis. David Swinbanks

\section{AMAZON FORESTS \\ Dispute enters new round}

\section{São Paulo}

Controversy over the extent of deforestation in Brazil's Amazon refuses to go away. Last week, the Brazilian Society for the Progress of Science (SPBC, Sociedade Brasileira para o Progresso da Ciência) stepped into the arena by setting up a panel of three scientists to sort out the continuing claims, counterclaims, retractions and accusations flowing from figures for rain-forest destruction announced by Brazilian President José Sarney (see Nature 338, 531; 13 April 1989).

Sarney's figures, based on data from the Institute for Space Research (INPE), showed just 5.12 per cent of legal Amazonia had been destroyed; a very different picture from the 12 per cent estimate produced in a recent report from the World Bank. INPE was quickly criticized for erroneously relating the area destroyed to the total area of the legal Amazon, rather than to the area of rain forests, which is smaller. But INPE's director, Márcio Nogueira Barbosa, then accused the World Bank report of making the same mistake.

Other members of INPE's staff attacked the haste with which the initial report was produced for the president's announcement, forcing them to use old Landsat pictures in some cases (see Nature 339, 86; 11 May 1989).

In a debate in São Paulo last week, Barbosa announced that the team that produced the data for the president's announcement may write a more detailed and technical account of the work. He also said that all the satellite images used are available to the scientific community to look at.

During the same debate, the head of the SBPC committee that is studying the issue, the geographer Aziz Ab'Saber, of the University of São Paulo, said that the scientific community is worried about the damage to the Space Institute's image and that they want to discuss the methodology used in the assessment of deforestation.

Ricardo Bonalume Neto 